\title{
Urea/Lactic Acid-based Topical Cream
}

National Cancer Institute

\section{Source}

National Cancer Institute. Urea/Lactic Acid-based Topical Cream. NCI Thesaurus. Code C116892.

A cream containing urea and the alpha hydroxy acid lactic acid, with potential keratolytic and hydrating activities. Upon topical application to the affected areas, the urea/lactic acid-based topical cream breaks down keratin and moisturizes the skin. 